\title{
MODEL KEAMANAN KENDARAAN RODA EMPAT DENGAN KARTU ID BERBASIS MIKROKONTROLER ARDUINO
}

\author{
Amir Hamzah Pohan ${ }^{1}$, Budi Dianika ${ }^{2}$, Liza binti Abdul Latiff ${ }^{3}$, Rudzidatul Akmam \\ Dziyauddin $^{4}$ \\ ${ }^{1,2}$ Teknik Elektro, Universitas Tama Jagakarsa (UTAMA) Jakarta \\ ${ }^{3,4}$ Electrical Engineering, Razak school, Universiti Teknologi \\ Malaysia Kuala Lumpur (UTM) \\ ${ }^{1,2}$ JL.TB Simatupang no 152 Tanjung Barat Jakarta Selatan 12530 Indonesia \\ 3,4Jalan Sultan Yahya Petra 54100 Kuala Lumpur, Malaysia \\ e-mail :amirhamzahpohan@gmail.com
}

\begin{abstract}
ABSTRAK
Kurangnya keamanan dan tingginya biaya keamanan ekstra sering menjadi masalah. Terkadang terasa percaya diri ketika diparkir atau ketika diparkir di tempat parkir, bahkan kendaraan terkunci. Tetapi kenyataan dari kasus pencurian saat ini adalah bahwa pencuri dapat dengan mudah membuka kunci kendaraan yang dipasang hanya dengan sepotong kawat atau dengan kunci buatan lainnya. Keahlian pencuri bahkan lebih besar, oleh karena itu kita harus memikirkan cara untuk menjaga kendaraan tetap terjaga dan bebas dari pencuri atau pencuri. Perkembangan dunia kejahatan dengan keahlian pencuri sangat tinggi, diperlukan gagasan inovasi dalam peralatan keselamatan kendaraan sehingga pembahasan penelitian ini adalah peralatan keselamatan kendaraan yang terdeteksi menggunakan (Radio Frequency Identification) berbasis mikrokontroler Arduino RFID. Desain keamanan ini tidak bergantung pada mekanik sebagai antarmuka tetapi menggunakan perangkat elektronik yaitu dengan menggunakan RFID. Metode ini dibagi menjadi tiga komponen utama, termasuk kartu ID, basis data dan basis data pembaca. Dengan metode yang dibuat pada RFID mampu mewujudkan perangkat keras keselamatan kendaraan dan menerapkan perangkat lunak keselamatan kendaraan juga mengetahui sistem kerja keselamatan kendaraan berdasarkan mikrokontroler Arduino Uno. Dalam pencurian kendaraan, pencuri dengan mudah membuka kunci pada kendaraan yang dipasang hanya dengan kawat atau dengan kunci lain dan masih ada kendaraan yang belum memiliki penggunaan teknologi tinggi dalam keamanan kendaraan. Dalam merancang sistem ini, penulis fokus membuat akses pengguna kendaraan menggunakan Kartu dan programnya menggunakan Arduino IDE, sedangkan untuk perangkat keras berupa pembaca RFID dan Mikrokontroler menggunakan modul yang sudah jadi dan tersedia di pasaran. Keselamatan kendaraan menggunakan RFID berfungsi pada kemampuan membaca modul RFID pada kartu.
\end{abstract}

Kata kunci : RFID, ID Card, Arduino Uno, Kendaraan

\section{ABSTRACT}

Lack of security and the high cost of extra security are often problems. Sometimes it feels confident when being parked or when parked in a parking lot, even the vehicle is locked. But the reality of theft cases today is that thieves can easily unlock the vehicle that is installed only with a piece of wire or with other artificial keys. The expertise of thieves is even greater, therefore we must think of ways to keep the vehicle awake and free from thieves or burglars. The development of the world of crime with the expertise of thieves is very high, the idea of innovation in vehicle safety equipment is needed so that the discussion of this research is vehicle safety equipment detected using (Radio Frequency Identification) based on Arduino microcontroller RFID. This security design does not rely on mechanics as an interface but uses an electronic device that is by using RFID. This method is divided into three main components, including ID card, data base and reader data base. With the method created on RFID is able to realize vehicle safety hardware and apply vehicle safety software also knows the work system of vehicle safety based on the Arduino Uno microcontroller. In vehicle theft, thieves easily open locks on vehicles that are 
IN F O R M A I I A

Jurnal Informatika, Manajemen dan Komputer, Vol. 12 No. 1 , Mei 2020

eISSN : 2580-3042

pISSN : 1979-0694

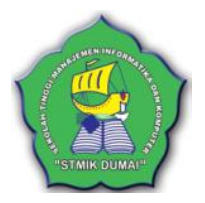

installed only by wire or with other keys and there are still vehicles that do not yet have the use of high technology in vehicle security. In designing this system, the author focuses on making vehicle user access using the Card and its program using the Arduino IDE, while for hardware in the form of RFID and Microcontroller readers using ready-made modules and available on the market. Vehicle safety using RFID works on the ability to read RFID modules on the card

Keywords: RFID, ID Card, Arduino Uno, Vehicle

\section{PENDAHULUAN}

Keamanan kendaraan roda empat masih belum tinggi saat diparkir atau ketika diparkir di depan halaman kendaraan dalam keadaan terkunci tetapi masih bisa dibuka dengan pintu kendaraan dengan mudah. Banyak kasus pencurian dengan mudah membuka kunci pada kendaraan yang dipasang hanya dengan teknologi sederhana seperti sepotong kawat membuka kunci pintu kendaraan atau kunci buatan lainnya. Keahlian membuka kunci pintu kendaraan roda empat semakin canggih, oleh karena itu harus diperhatikan bagaimana menjaga kendaraan roda empat tetap terkunci dan terkontrol. Banyak cara untuk membuat keamanan kendaraan termasuk memasang kunci tambahan dalam jumlah besar, tetapi dengan kontrol pada model terbaru akan membuatnya lebih aman dan lebih nyaman untuk digunakan.

Perkembangan dunia teknologi sangat tinggi, sehingga diperlukan gagasan model peralatan keselamatan kendaraan yang inovatif (Radio Frequency Identification) berbasis mikrokontroler Arduino dengan keamanan tinggi. Desain keamanan ini tidak bergantung pada mekanik sebagai antarmuka tetapi menggunakan perangkat elektronik yang diprogram. Tidak seperti kunci mekanis, kunci elektronik dalam desain keamanan ini menggunakan RFID sebagai pembuka. Model dengan sistem RFID dibagi menjadi tiga komponen utama, termasuk kartu, basis data, dan pembaca basis data. Kartu RFID berguna sebagai sarana mengidentifikasi objek di mana ada kode tentang suatu objek. Dan pembaca RFID digunakan sebagai pembaca data pada Kartu RFID. Sedangkan basis data pemindaian digunakan sebagai pencarian dan menyimpan informasi tentang benda-benda yang dimiliki oleh kartu RFID. RFID adalah perpanjangan dari sistem identifikasi sebelumnya, Barcode.

Perbedaan antara RFID dan kode terletak pada cara pembacaannya, yaitu pembacaan perangkat yang digunakan untuk pelabelan. Untuk barcode, pembacaan biasanya dilakukan langsung di posisi kartu dengan pembaca harus tepat. Kalau tidak, kartu tidak dapat dibaca oleh sensor. Bukan dengan RFID, yang hanya dengan menyimpan kartu di pembaca, sehingga kartu dapat diidentifikasi. Prosesor data berfungsi untuk memproses input data untuk diproses sebagai identifikasi input. Prosesor perangkat terdiri dari mikrokontroler Aduino Uno. Perangkat drive adalah Relay sebagai output dari mikrokontroler. Perangkat identifikasi terdiri dari pembaca RFID dan kartu. Pembaca dipasang di mobil, meningkatkan keamanan kendaraan karena tidak terlihat dari luar. Jika Anda ingin mengubah kunci, Anda tidak harus membongkar kunci seperti model asli, tetapi hanya mengganti program yang ada pada RFID dan pembaca.

\section{METODOLOGI PENELITIAN}

Identifikasi kebutuhan dalam merancang perangkat keselamatan kendaraan menggunakan (Radio Frequency Identification) RFID dengan mikrokontroler berbasis Arduino diperlukan beberapa komponen di antaranya:

a. Adaptor $12 \mathrm{~V}$ untuk memasok tegangan agar berfungsi dengan baik.

b. Regulator IC 7805 menurunkan tegangan dua belas volt menjadi lima

c. Sistem mikrokontroler Arduino sebagai sistem pemrosesan INPUT / OUTPUT.

d. Relay sebagai kelanjutan dari output mikrokontroler.

e. LCD 16x2 untuk layar monitor terkunci atau tidak.

f. Sirkuit I2C untuk memproses data dari mikrokontroler ke LCD 16x2.

g. Modul RFID (Radio Frequncy Identification) sebagai sarana menerapkan teknologi RFID.

h. Bel untuk alarm atau tanda-tanda bekerja perangkat.

i. LED untuk indikator yang berfungsi.

j. USB untuk mengunggah program ke mikrokontroler.

k. Kabel jamper.

Berdasarkan identifikasi persyaratan, beberapa spesifikasi komponen atau sirkuit diperlukan sebagai berikut: 
IN F ORMA T I K A

Jurnal Informatika, Manajemen dan Komputer, Vol. 12 No. 1 , Mei 2020

elSSN : 2580-3042

pISSN : 1979-0694

a. Perangkat Power Supply yang digunakan adalah $12 \mathrm{~V}$ Adapter.

b. Perangkat kontrol mikrokontroler pada perangkat keselamatan kendaraan menggunakan (Radio Frequency Identification) RFID menggunakan mikrokontroler Arduino sebagai perangkat pengendali mikrokontroler.

c. Relay sebagai kelanjutan dari output mikrokontroler.

d. Dipimpin sebagai indikator work tool

e. Modul RFID sebagai modul untuk membaca kartu tag yang kemudian diproses sebagai data input.

f. Desain keselamatan kendaraan digunakan sebagai model kinerja alat.

g. Kabel jamper untuk menghubungkan mikrokontroler ke komponen lain.

Berikut ini adalah gambar dari diagram alir untuk alur kerja perangkat keselamatan kendaraan menggunakan RFID berdasarkan Arduino Microcontrollers dalam gambar.

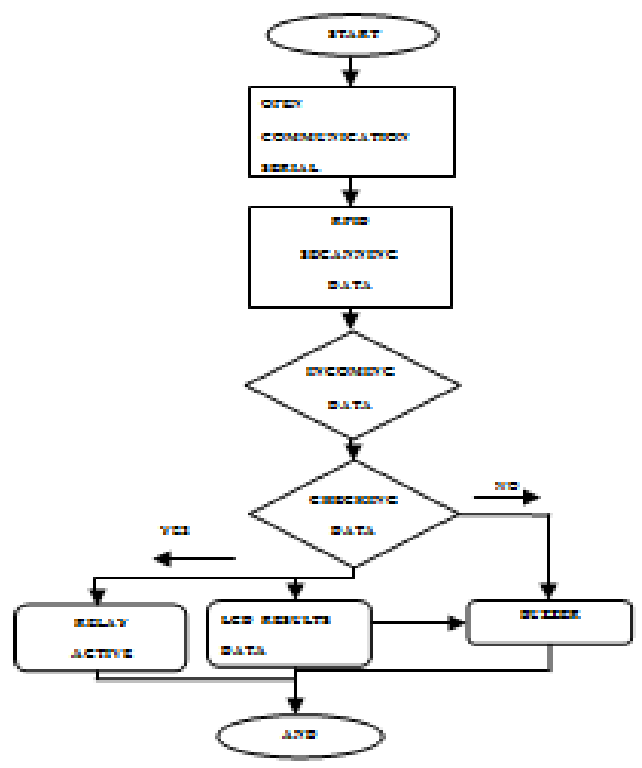

Gambar 1. Diagram alir keselamatan kendaraan menggunakan RFID

\section{Penjelasan FlowChart}

a. Buka komunikasi serial.

Ketika perangkat dihidupkan dengan RFID, sistem kontrol akan memproses komunikasi sehingga cara untuk informasi yang dibaca oleh RFID melewati komunikasi serial sehingga pengontrol diproses.

b. Pembacaan data Pembaca RFID.

Sistem RFID termasuk sensor RFID ketika diaktifkan akan bekerja dalam pemindaian data yang masuk melalui pembaca (antena). Data yang masuk akan diproses oleh pengontrol dan disesuaikan dengan informasi ID yang diprogram.

\section{c. Data yang Masuk}

Informasi pembaca RFID (Antena) akan masuk melalui sesi pemanggil ini yang akan diproses oleh pengontrol.

d. Memeriksa Basis Data

Semua informasi yang berhasil diproses akan diperiksa keakuratannya dengan informasi yang terdapat dalam informasi program pada pengontrol.

\section{e. Relay aktif}

Jika pembacaan data cocok dengan yang ada pada basis data mikrokontroler, mikrokontroler akan mengeluarkan output perintah sehingga relai berada dalam kondisi aktif yang membuat keselamatan kendaraan berfungsi

\section{Manufacturing of Tools}

\section{a. Desain perangkat keras.}

Perangkat keselamatan kendaraan menggunakan RFID dengan Mikrokontroler Berbasis Arduino.

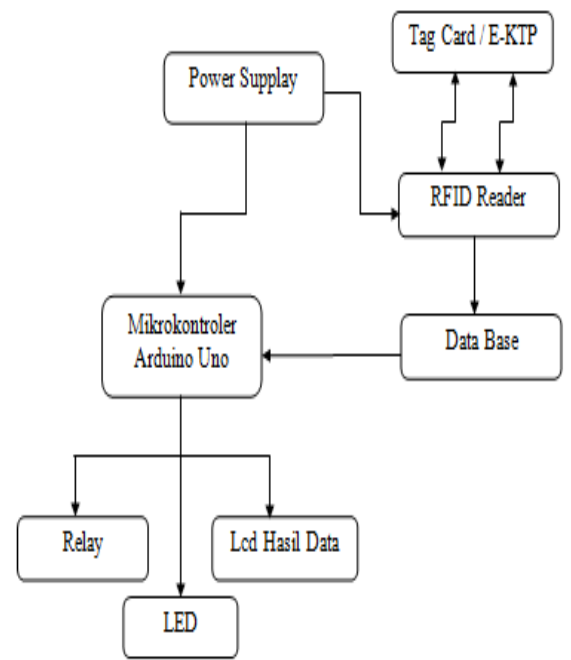

Gambar 2 Diagram Sistem Blok

1. Cara kerja bagian input

Bagian input adalah kartu yang dibaca oleh kepala RFID dan informasi yang dibaca diperiksa dan terus diproses oleh pengontrol apakah sesuai dengan basis data atau tidak. 
I N F O R M A T I K A

Jurnal Informatika, Manajemen dan Komputer, Vol. 12 No. 1 , Mei 2020

eISSN : 2580-3042

pISSN : 1979-0694

2. Mikrokontroler Arduino

Sistem kontrol yang digunakan adalah sistem mikrokontroler ATmega 328P dengan desain yang disesuaikan agar sesuai dengan modul RFID yang digunakan.

3. Blok Output

Dalam sistem ini fungsi relai sebagai OUTPUT yang akan bertindak sebagai penghubung dan pemutus.

4. Perencanaan Rantai Pasokan Daya

Power Supply sangat penting untuk memasok tegangan ke mikrokontroler dan sistem relay. Catu Daya pada alat ini menggunakan adaptor $12 \mathrm{~V}$ yang akan dikurangi menjadi $5 \mathrm{~V}$

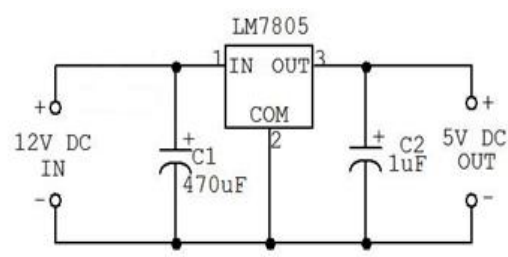

Gambar 3 Blok Pengurangan Tegangan

Gambar 3 adalah bagian dari blok pengurang tegangan dengan fungsi mengurangi tegangan yang masuk melalui jack DC menggunakan regulator 7805 yang akan menghasilkan tegangan 5 volt agar sesuai dengan kebutuhan pasokan sistem mikrokontroler.

\section{b. Desain perangkat lunak}

Aplikasi dan modifikasi syntac perangkat lunak pada mikrokontroler Atmega dimaksudkan untuk membuat basis data terprogram yang berisi ID seri kartu tag yang digunakan dan untuk memproses input data yang diproses menjadi perintah untuk proses aktivasi relai. Ini akan mengambil bentuk inisialisasi dan penulisan daftar program.

Inisialisasi model mikrokontroler yang digunakan dalam Gambar 4

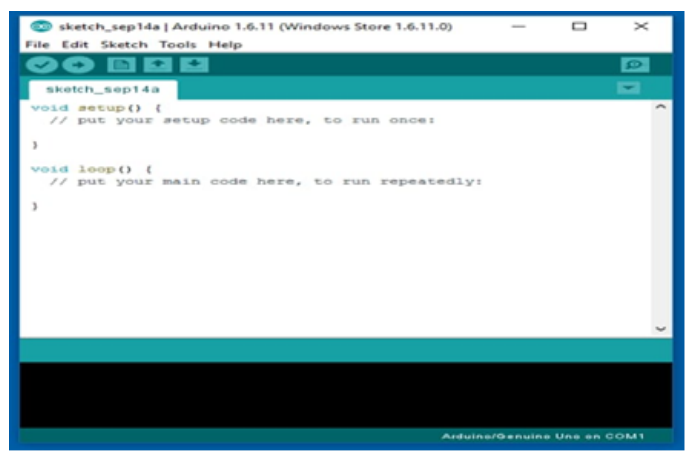

Gambar 4. Inisialisasi Mikrokontroler
Inisialisasi Port Serial

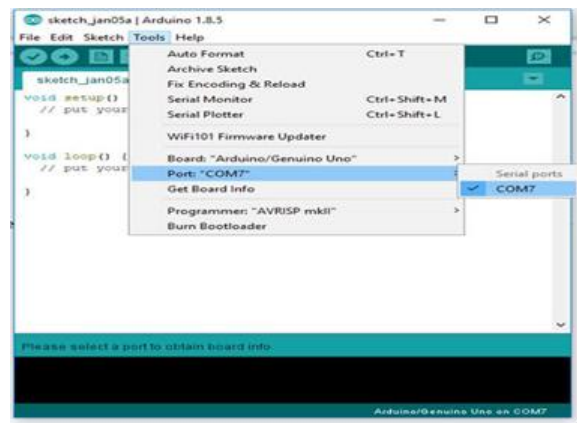

Gambar 5 Tampilan alat program port serial IDE Arduino

Dalam membuat daftar program menggunakan Arduino IDE yang menggunakan bahasa $\mathrm{C}$ dasar

\section{Dasar-Dasar Program}

a. Pengaturan kosong ()

Berisi kode pengaturan sekali selama waktu untuk tidak mengatur ulang. Merupakan bagian dari persiapan atau inisialisasi program.

b. Void loop ()

Berisi kode pengaturan yang akan diproses terus menerus. Ini untuk program utama.

c. Instruksi percabangan jika dan jika-lain

Perintah if dan if-else akan diuji apakah taat atau tidak. Jika tidak dipatuhi, perintah selanjutnya akan dilewati, tetapi jika dipatuhi, maka perintah akan dieksekusi.

d. Instruksi looping loop

Loop for-loop akan membuat sejumlah loop di bloknya, yaitu sebanyak nilai counter-nya.

e. Input Output Digital

1. pinMode (), disimpan dalam pengaturan kosong (), digunakan untuk mengatur pin input / output digital, untuk INPUT atau OUTPUT, dengan model penulisan berikut: pinMode (3, OUTPUT); // jadikan D3 output.

2. digitalRead (), Digunakan untuk membaca sinyal digital yang masuk, instruksi digitalRead () digunakan, dengan model tertulis berikut: tombol 45int $=$ digitalRead (2); // membaca sinyal yang masuk pada D2

3. digitalWrite (), digunakan untuk mengeluarkan sinyal digital, dengan format penulisan 
I N F O R M A T I K A

Jurnal Informatika, Manajemen dan Komputer, Vol. 12 No. 1 , Mei 2020

eISSN : 2580-3042

pISSN : 1979-0694

berikut: digitalWrite ( $3, \mathrm{HIGH})$; // berikan sinyal TINGGI pada D3.

\section{Komunikasi}

a. Instruksi Serial.begin (), berguna untuk pengaturan kecepatan komunikasi, nilai 9600

b. Instruksi Serial.available (), berfungsi untuk mendapatkan banyak karakter atau byte yang telah disimpan dalam serial.

c. Instruksi Serial.read (), digunakan untuk membaca data yang telah diterima pada port serial.

d. Instruksi Serial.print (), digunakan untuk mencetak data ke port serial.

e. Instruksi Serial.write (), digunakan untuk mengirim data dalam bentuk biner, satu byte data per transmisi.:

\section{Fungsi Program}
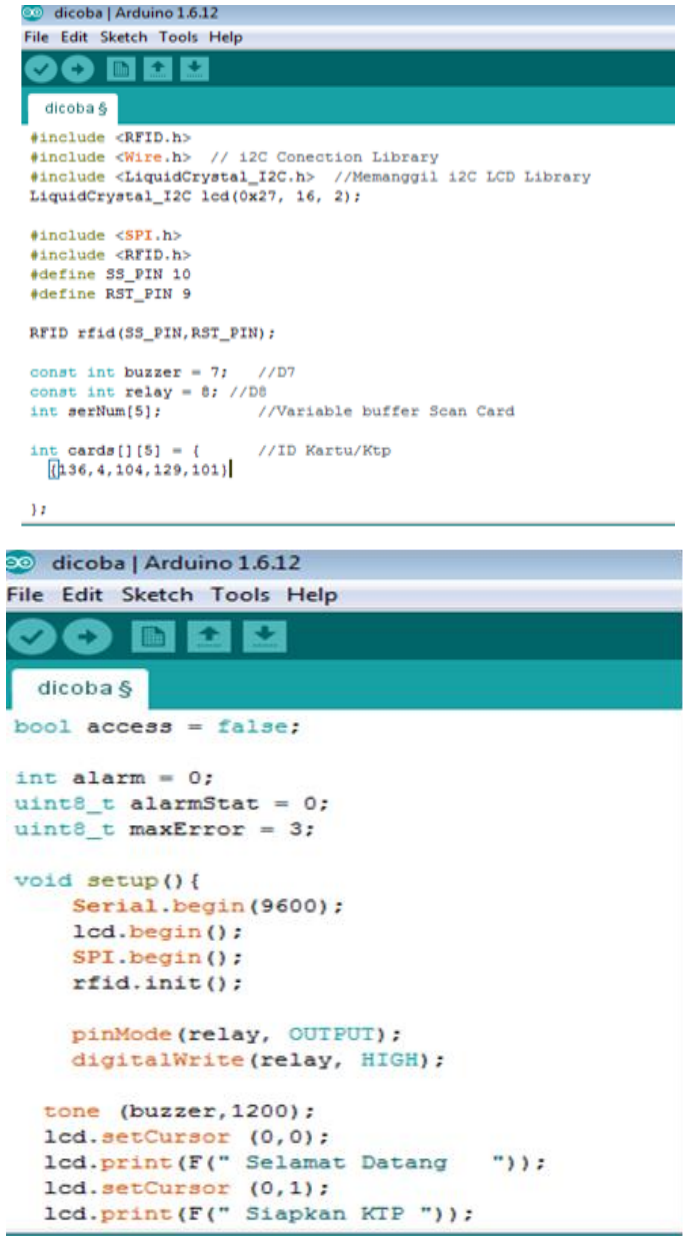

Gambar 6. Instruction serial ()

\section{Alat Pengujian}

Alat pengujian dilakukan untuk mendapatkan data penelitian. Dalam pengujian alat digunakan dengan 2 tes, yaitu:

a. Uji fungsional. Pengujian digunakan dengan menguji setiap bagian dari alat sesuai dengan karakteristik dan kegunaan masing-masing alat. Pengujian digunakan untuk mengetahui apakah alat tersebut bekerja dengan baik.

b. Alat uji kinerja dilakukan dengan melihat fungsi alat. Hal-hal yang harus diperhatikan adalah: sirkuit sistem minimum, kerja sensor RFID, kartu RFID / E-KTP dan relay. Dari percobaan ini karya perangkat yang dibuat akan diketahui.

\section{Pengoperasian Alat}

Pengoperasian alat ini dapat dilakukan dengan cara-cara berikut:

a. Pastikan alat terhubung ke tegangan $12 \mathrm{~V}$ DC yang telah diturunkan menggunakan regulator IC 7805 ke 5V.

b. Hubungkan sirkuit sensor RFID, mikrokontroler Arduino, dan relay.

c. Tunjukkan kartu RFID / E-ID dengan sensor RFID untuk mengoperasikan keselamatan kendaraan.

\section{HASIL DAN PEMBAHASAN}

Metode pengujian dalam penelitian ini dimulai dengan pengujian Mikrokontroler Arduino Uno. Perlunya pengujian mikrokontroler untuk mengetahui bahwa mikrokontroler bekerja dengan baik atau tidak karena ini sangat penting mengingat integrasi semua sistem utama adalah mikrokontroler. Selanjutnya diuji adalah kartu RFID dan RFID, Sixteen $x$ Two LCD, dan akhirnya IC Regulator Tegangan.

\section{Pengujian sistem Arduino Uno}

Tujuan pengujian mikrokontroler adalah untuk mengetahui bahwa setiap port yang digunakan pada mikrokontroler Arduino Uno berfungsi baik dengan nilai tegangan 4,5 - 5 Volt. Pengujian terutama dilakukan pada port yang digunakan. Pengujian dilakukan dengan menghubungkan probe positif AVO ke port yang sedang diuji dan Probe Negatif di Lapangan. Hasilnya adalah nilai 4,9 V yang berarti bahwa logika "1" menunjukkan bahwa sistem minimum berfungsi dengan baik. 
IN F ORMA T I K A

Jurnal Informatika, Manajemen dan Komputer, Vol. 12 No. 1 , Mei 2020

eISSN : 2580-3042

pISSN : 1979-0694

Tabel 1 Hasil Tes untuk Port Modul Arduino

\begin{tabular}{|c|c|c|c|c|c|c|}
\hline \multirow[t]{2}{*}{$\begin{array}{l}\text { Port yang } \\
\text { digunalkan }\end{array}$} & \multicolumn{6}{|c|}{$\begin{array}{l}\text { Nilai tegangan } \\
\text { keluaran (Volt) }\end{array}$} \\
\hline & $v_{2}$ & $v_{2}$ & $\mathrm{v}_{z}$ & $\mathrm{v}_{\mathrm{s}}$ & $\mathrm{v}_{s}$ & $R$ \\
\hline D7 & 4,810 & 4,810 & 4,830 & 4,810 & 4,810 & 4.810 \\
\hline D8 & 4,800 & 4,810 & 4,810 & 4,800 & 4,800 & 4,800 \\
\hline D9 & 4,810 & 4,810 & 4,800 & 4,810 & 4,810 & 4,810 \\
\hline D10 & 4,800 & 4,800 & 4,800 & 4,800 & 4,810 & 4,800 \\
\hline D11 & 4,800 & 4,800 & 4,820 & 4,800 & 4,800 & 4.800 \\
\hline D12 & 4,830 & 4,810 & 4,800 & 4,800 & 4,800 & 4,800 \\
\hline D13 & 4,800 & 4,800 & 4,810 & 4,800 & 4,830 & 4,800 \\
\hline GDN & GDN & GDN & GDN & GDN & GDN & GDN \\
\hline $3.3 \mathrm{~V}$ & 3,285 & 3,286 & 3,285 & 3,280 & 3,285 & 3.285 \\
\hline $5 \mathrm{~V}$ & 5,000 & 5,000 & 5,000 & 5,000 & 5,000 & 5,000 \\
\hline A4 & 4,860 & 4,860 & 4,860 & 4,870 & 4,860 & 4,860 \\
\hline $\mathrm{A} 5$ & 4,830 & 4,800 & 4,810 & 4,810 & 4,810 & 4,810 \\
\hline
\end{tabular}

Informasi:

V: Data Tegangan

Port D7: Digunakan untuk buzzers

Port D8: Digunakan untuk relay

Port D9: Digunakan untuk RST RFID Port RC522

Port D10: Digunakan untuk Port RFID SDA RC522

Port D11: Digunakan untuk Port RFID RC522 MOSI

Port D12: Digunakan untuk Port MISO RFID RC522

Port D13: Digunakan untuk Port RFID SCK RC522

Port A4: Digunakan untuk Port SDA LCD 16 X 2

Port A5: Digunakan untuk Port LCD 16 X 2 SCL

Port 3.3V: Output

Port 5 V: Output

\section{Pengujian Sensor RFID RC522}

Pengambilan data pengukuran jarak dilakukan selama pengumpulan $5 \mathrm{X}$.
Tabel 2 Menguji sensor jarak dengan Kartu RFID RC522 dan beberapa Kartu id..

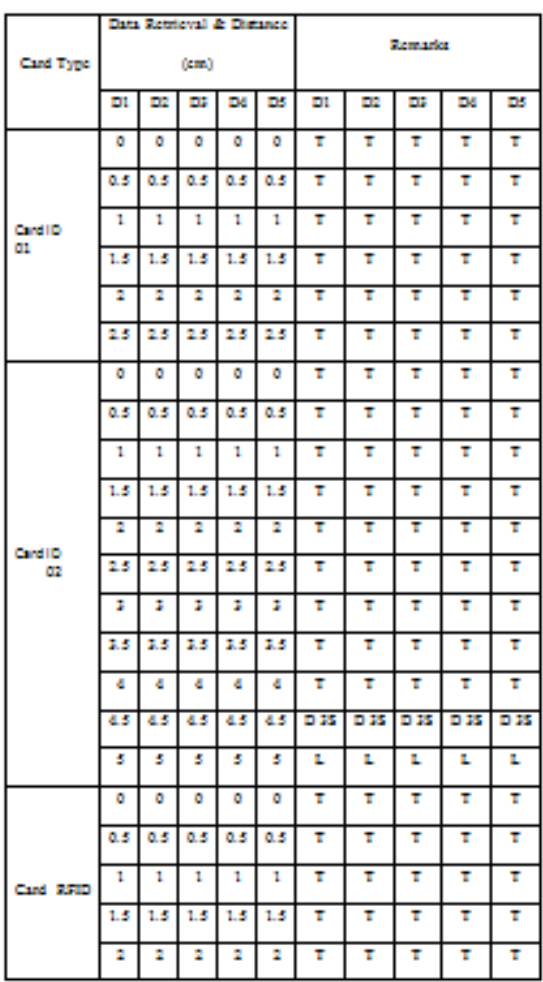

Keterangan :

T: Dapat dibaca

L: Kerugian

D 3 S: Delay 3 Second D 4 S: Delay 4 Second

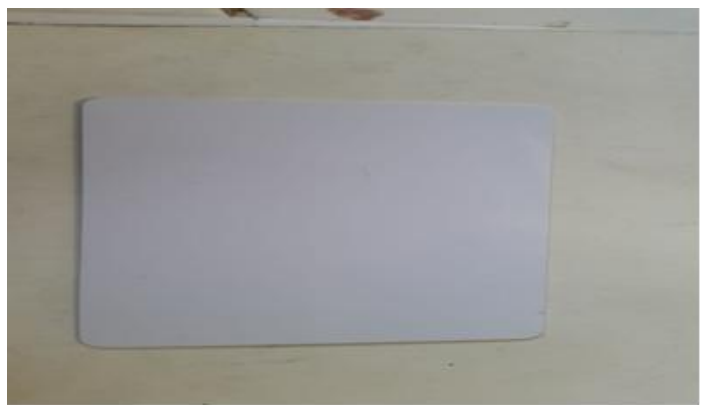

Gambar 7. RC522 Kartu RFID

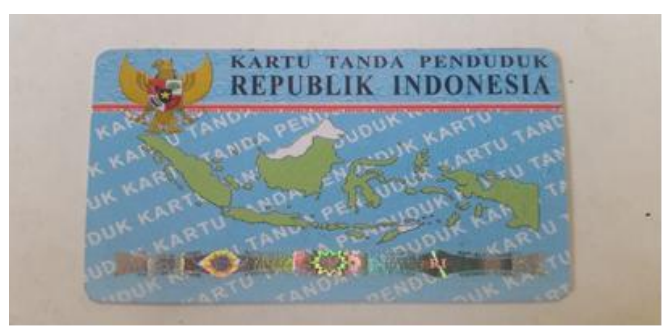

Gambar 8. Kartu ID 
IN F ORMA T I K A

Jurnal Informatika, Manajemen dan Komputer, Vol. 12 No. 1 , Mei 2020

eISSN : 2580-3042

pISSN : 1979-0694

\section{Pengujian Hambatan Material}

Tabel 3. Material Barrier Material yang dapat ditembus RFID Reader

\begin{tabular}{|l|c|c|}
\hline \multirow{2}{*}{ Tipe Material } & \multicolumn{2}{c|}{ Kemampuan } \\
\cline { 2 - 3 } & Dapat Tembus & Tidal: Tembus \\
\hline Plastik & $v$ & \\
\hline Kertas & $v$ & \\
\hline Kain & $v$ & \\
\hline Triplek & & - \\
\hline Daun & & - \\
\hline Alumunium & & - \\
\hline Besi & & - \\
\hline Seng & & - \\
\hline
\end{tabular}

\section{Pengujian Tegangan}

a. Pengukuran tegangan pada modul Arduino dari port D7 dengan $5 \mathrm{x}$ percobaan menunjukkan hasil tegangan V1 4.800 volt, V2 4.810 volt, V3 4.820 volt, V4 4.810 volt, V5 4.810 volt, tegangan puncak 5.000 Volt

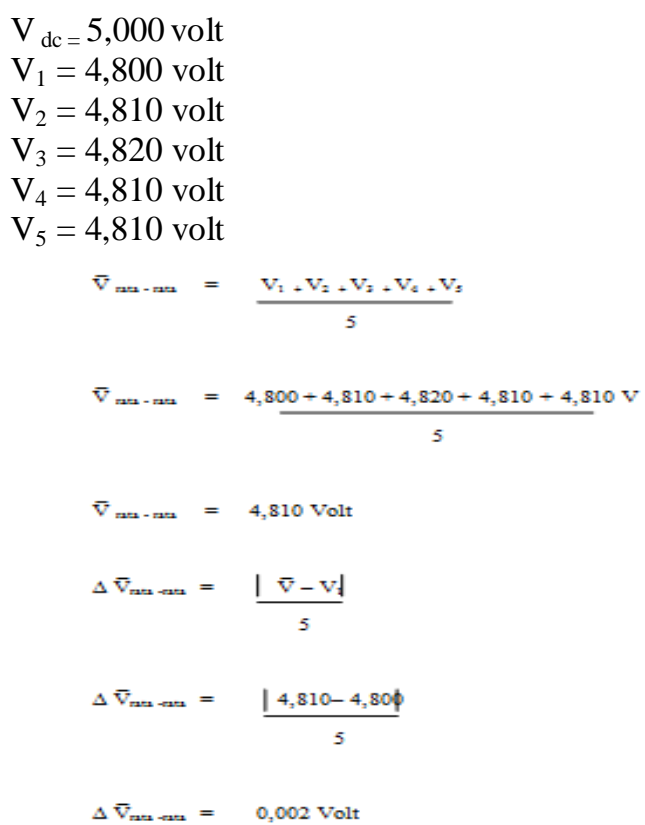

Tegangan pada Modul Arduino Port D 7 adalah $4.810 \pm 0,002$ Volt

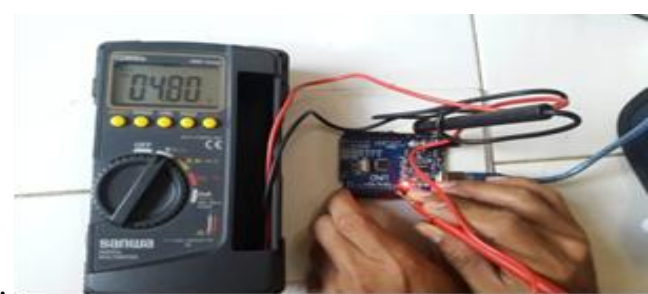

Gambar 9. Pengukuran Tegangan pada Modul Pelabuhan Arduino D9 - D13. b. Pengukuran tegangan pada output LCD $16 \mathrm{x}$ 2 menunjukkan Tegangan dalam $5 \mathrm{x}$ percobaan rata-rata $\quad 4,860$ volt. Jadi diperoleh:

$$
\Delta \overline{\mathrm{V}}_{n \mathrm{nas}}=\frac{|4,870-4,860|}{5}=0,002 \text { Volt }
$$

Jadi tegangan yang dapat digunakan adalah: $4.860 \pm 0,002$ Volt

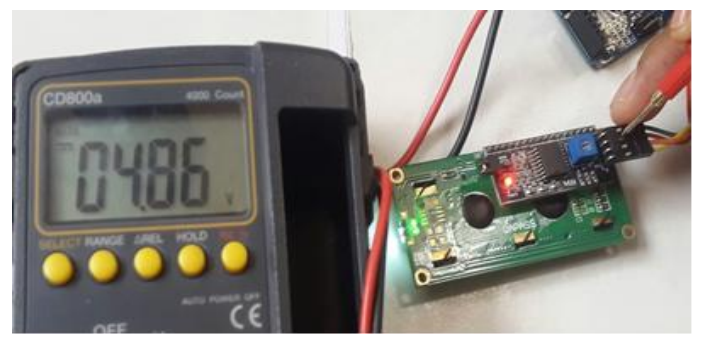

Gambar 10. Pengukuran Tegangan pada LCD 16 $\mathrm{x} 2$

Pengukuran tegangan pada output Voltage Regulator IC 7805 menunjukkan tegangan dalam 5 x percobaan 5 volt. Jadi diperoleh:

$$
\frac{|5,000-5,000|}{5}=0 \text { Volt }
$$

Jadi tegangan yang didapat adalah: 5,000 \pm 0 Volts

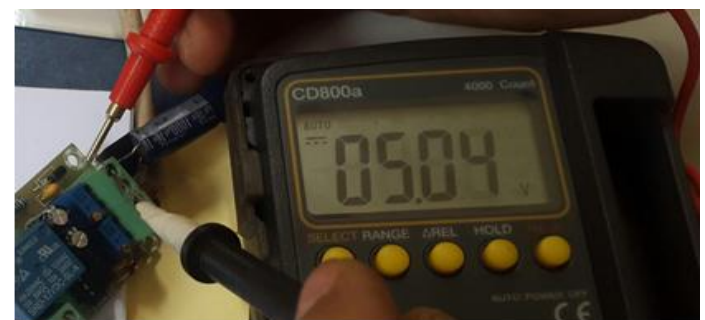

Gambar 11. Pengukuran Tegangan pada IC Regulator 7805

Tabel 4. Hasil Pengukuran Tegangan

\begin{tabular}{|c|c|c|}
\hline Tegangan & Nilai & Hasil Tegangan \\
\hline Modul Arduino & $4,810 \mathrm{v}$ & $4,810=0,002$ Volt \\
\hline LCD $16 \times 2$ & $4,862 \mathrm{v}$ & $4,860=0,002$ Volt \\
\hline IC Regulator 7805 & $5 \mathrm{v}$ & $5,000=0$ Volt \\
\hline
\end{tabular}


IN F ORMA TIK

Jurnal Informatika, Manajemen dan Komputer, Vol. 12 No. 1 , Mei 2020

eISSN : 2580-3042

pISSN : 1979-0694

\section{KESIMPULAN}

Sensor RFID dapat membaca kartu RFID dengan jarak maksimum sentimeter. Jarak maksimum dapat dideteksi pada jarak $2 \mathrm{~cm}$. Jika Anda menggunakan Kartu ID, jarak maksimum hanya 4,5 cm dengan jeda 3 detik. RFID / ID Card adalah perangkat yang digunakan untuk keselamatan kendaraan dengan menghadapi sensor RFID. Bahan yang dapat ditembus oleh RFID adalah bahan yang tidak terbuat dari logam karena semua benda terbuat dari logam (besi, seng, aluminium, dll.). Karena sensor RFID mengambil model induksi dari koil yang ada pada sensor RFID, sehingga ketika dihadapkan dengan bahan logam yang sama, induksi akan diserap, seperti dalam magnet. Secara teoritis, seluruh sirkuit keselamatan kendaraan yang didasarkan pada mikrokontroler Arduino disuplai menggunakan tegangan Dc 12 volt dari adaptor yang diturunkan menggunakan regulator IC 7805 ke 5 volt Dc. Dalam pengujian tegangan kali ini, regulator IC 7805 mendapat tegangan output 5.000 volt Dc dengan tegangan $5.000 \pm 0$ Volt. Port tegangan modul Arduino D7 - D13 mendapatkan 4.810 volt Dc dengan persentase voltase $4.810 \pm 0,002$ Volt. Tegangan LCD $16 \mathrm{x}$ 2 mendapatkan 4.862 Volt Dc dengan persentase tegangan $4.860 \pm 0,002$ Volt, semua sirkuit input dan output mendapatkan 5 volt Dc.

\section{REFERENSI}

Khan, Safayet Rahman, Obaidur Ehsan, Md. Design and Fabrication of a Password Protected Vehicle Security and Performance Monitoring System. DOI: 10.1109/R10HTC.2017.8289022 Conference: 2017 IEEE Region 10 Humanitarian Technology Conference (R10-HTC), At Dhaka, Bangladesh, 2017/12/23.

Kunnu Purwanto,Iswanto,Tony Khristanto Hariadi, Muhammad Yusvin Muhtar"Microcontroller-based RFID, GSM and GPS for Motorcycle Security System" (IJACSA) International Journal of Advanced Computer Science and Applications, Vol. 10, No. 3, 2019..

Pritpal Singh, Tanjot Sethi, Bibhuti Bhusan Biswal, and Sujit Kumar Pattanayak. A Smart Anti-theft System for Vehicle Security. International Journal of Materials, Mechanics and Manufacturing, Vol. 3, No. 4, November 2015.

T.Nandhini, J.Shalini, T. Sai Sangeeetha, D.Gnanaprakasam. Underground Cable
Fault Detection using Arduin. International Journal of Engineering Science and Computing, April 2017 Volume 7 Issue No.4.

Keval B Trivedi,Dr. Chirag Vibhakar, Prof. Ravin Sardhara. Differential Protection Of Transformer Using Arduino With Gsm And Voice Circuit. International Journal Of Novel Research And Development (C) 2017 Ijnrd | Volume 2, Issue 4 April 2017 | Issn: 2456-4184

Karl Haebler, Anson Lau, Jackson Qiu, Michal Bajcsy. High Resolution Multi-grating Spectrometer Controlled by an Arduino University of Waterloo, Waterloo, Ontario, Canada.

Narendra Kumar Sharivas, Lokesh Kumar, Deepak Agrawal, Yuvraj Verma, Ashwani Sahu,Sandeep Somkuwar. Human Assistance Robot by Using Arduino. International Journal of Scientific Research in Computer Science, Engineering and Information Technology@ 2017 IJSRCSEIT | Volume 2 | Issue 3 | ISSN : 2456-3307.

Vishwanathraddi A, Kalyan Chakravarthi M. Arduino-Based Wireless Mobot. Advances In Smart Computing And Bioinformatics Full Proceeding Paper Special Issue (April)20177.

JoelSachin, Kiran Rana Gill. Anti-Theft System For Vehicles Using Fingerprint Sensor International Journal Of Scientific \& Engineering Research, Volume 7, Issue 7, July-2016 ISSN 2229-5518.

M.Karthick, M.N.Chandhan, R.Gobinath, D.Gokul, M.GokulHai. Fingerprint Ignition System in Bike (Two wheeler). EPH International Journal of Science and Engineering ISSN: 2454 - 2016.

Shubham Swaraj, Ass. Prof. Richa R Khandelwal. RFID Based Automatic Vehicle Identificationfor Access Control International Journal of Innovative Research in Computer and Communication Engineering (An ISO 3297: 2007 Certified Organization)Vol. 4, Issue 2, February 2016 